\title{
Prologue: 2019 Annual Meeting of the Group for Research and Assessment of Psoriasis and Psoriatic Arthritis (GRAPPA)
}

\author{
Kristina Callis Duffin, Dafna D. Gladman (iD, Niti Goel ${ }^{\mathbb{D}}$, and Alice B. Gottlieb
}

\begin{abstract}
The 2019 Annual Meeting of the Group for Research and Assessment of Psoriasis and Psoriatic Arthritis (GRAPPA) was held in Paris, France, and was attended by rheumatologists, dermatologists, representatives of biopharmaceutical companies, and patients. As in previous years, GRAPPA members held a symposium for trainees to discuss their research in psoriatic disease with experts in the field. Other subjects featured during the annual meeting included a composites workshop to review continuous composite measures; the GRAPPA-Collaborative Research Network's third annual meeting; the need for a precision medicine approach to the treatment of psoriatic disease; updates from working groups in International Dermatology Outcome Measures and Outcome Measures in Rheumatology; a debate on the effectiveness of methotrexate in the treatment of psoriatic arthritis (PsA); updating recommendations for optimal treatment approaches for patients with PsA; an update on GRAPPA's research and educational projects; and the GRAPPA ultrasound (US) working group's goal to optimize the evaluation of enthesitis in patients with PsA using US through the development of a diagnostic US enthesitis tool. In this Prologue, we introduce the papers that summarize that meeting. (J Rheumatol Suppl. 2020 June;96:1-3; doi:10.3899/jrheum.200119)
\end{abstract}

Key Indexing Terms: PSORIASIS

OMERACT

\section{INTERNATIONAL DERMATOLOGY OUTCOME MEASURES}

The 2019 annual meeting of the Group for Research and Assessment of Psoriasis and Psoriatic Arthritis (GRAPPA) was held in July in Paris, France, aand was attended by investigators in rheumatology and dermatology, representatives of biopharmaceutical companies, and patient research partners (PRP; Table 1), who discussed individual and

From GRAPPA (Group for Research and Assessment of Psoriasis and Psoriatic Arthritis), Seattle, Washington; University of Utah, Salt Lake City, Utah, USA; University of Toronto, Krembil Research Institute, Toronto Western Hospital, Toronto, Ontario, Canada; Duke University School of Medicine, Durham, North Carolina, USA; Department of Dermatology, Icahn School of Medicine at Mount Sinai, New York, New York, USA

As part of the supplement series GRAPPA 2019, this report was reviewed internally and approved by the Guest Editors for integrity, accuracy, and consistency with scientific and ethical standards.

Financial support to enable these meetings was provided in 2019 by AbbVie, Amgen, Boehringer Ingelheim, Bristol-Myers Squibb, Celgene, Gilead, Janssen, Eli Lilly \& Co., Novartis, Pfizer, Sun Pharma, and UCB. In addition, our Innovation Partner in 2019 was Nordic Bioscience. K. Callis Duffin, MD, University of Utah, and President, GRAPPA; D.D. Gladman, MD, FRCPC, Professor of Medicine, University of Toronto, Senior Scientist, Krembil Research Institute, Toronto Western Hospital, and co-chair, GRAPPA Publication Committee; N. Goel, MD, Patient Research Partner, Adjunct Assistant Professor, Duke University School of Medicine, and co-chair, GRAPPA Publication Committee; A.B. Gottlieb, MD, PhD, Clinical Professor of Dermatology, Department of Dermatology, Icahn School of Medicine at Mount Sinai, and co-chair, GRAPPA Publication Committee.

Address correspondence to Dr. K. Callis Duffin, University of Utah, 4 A330 Dermatology SOM, 30 North 1900 East, Salt Lake City, Utah 84132,USA.E-mail:Kristina.callis@hsc.utah.edu collaborative research and educational initiatives in psoriasis and psoriatic arthritis (PsA). Currently, there are 981 international GRAPPA members, including investigators in rheumatology and dermatology $(n=673)$, representatives of biopharmaceutical companies $(n=212)$, PRP $(n=27)$, and other members $(n=69)$. Reports of previous yearly meetings have been published elsewhere ${ }^{1-10}$.

A Trainees Symposium was held prior to the annual meeting, in which rheumatology and dermatology researcher-trainees from Europe, North America, and South America who are current GRAPPA members or who were nominated by GRAPPA members presented and discussed their studies with experts in the field. A total of 54 abstracts were submitted and ranked by a committee of reviewers. Five trainees with the highest-scored abstracts were invited to deliver oral presentations; all trainees presented posters that outlined key aspects of their research. Dr. Christopher T. Ritchlin (Rheumatologist, Rochester, New York, USA) and Dr. Wolf-Henning Boehncke (Dermatologist, Geneva, Switzerland) co-chaired the symposium. GRAPPA members discussed the findings presented by trainees and suggested how trainees might further their current research projects ${ }^{11}$.

During the 2019 GRAPPA annual meeting, a composites workshop was held in which a review of continuous composite measures was conducted during an introductory workshop, followed by 10 breakout group sessions, and a final plenary session for feedback and voting. Feedback and voting during the workshop showed that the GRAPPA

Personal non-commercial use only. The Journal of Rheumatology Copyright @ 2020 . All rights reserved. 
Table 1. GRAPPA 2019 Annual Meeting attendance.

\begin{tabular}{lc}
\hline Participant Type & Total \\
\hline Dermatologist & 21 \\
Rheumatologist & 112 \\
PRP & 12 \\
Trainees & 25 \\
Industry & 54 \\
Other & 5 \\
Total & 229 \\
\hline
\end{tabular}

GRAPPA: Group for Research and Assessment of Psoriasis and Psoriatic Arthritis; PRP: patient research partner.

membership supports the need for a continuous composite measure of disease activity for use in routine clinical care, the separate measurement of disease impact and activity, and the testing of modifications to candidate instruments rather than the development of new measures ${ }^{12}$.

A symposium was held that discussed the need for a precision medicine approach to the treatment of psoriatic disease that takes into account an individual patient's variations in genes, proteins, environment, and lifestyle. In addition, reports on advances that are being made to address areas of unmet need in PsA, notably the use of proteomic approaches, were presented with suggestions that combine genetic and protein data (proteogenomics). Finally, a discussion was held on the progress that is being made in 2 large-scale, multipartner studies that are focused on the development of a precision medicine approach to the treatment of skin psoriasis ${ }^{13}$.

The GRAPPA-Collaborative Research Network (CRN) held its third annual meeting prior to the GRAPPA 2019 annual meeting. The GRAPPA-CRN group presented its progress in selecting a database platform; identifying items to include in an electronic case report form (eCRF); and developing standardized operating procedures (SOP) for the collection, processing, storage, and transport of biomaterial. A pilot investigator-initiated study was also proposed that would allow for the testing of both the eCRF and $\mathrm{SOP}^{14}$.

The effectiveness of methotrexate (MTX) in the treatment of PsA was debated. Clinical study data and the patient experience were discussed, and the efficacy, tolerability, and toxicity of MTX for both skin and musculoskeletal manifestations were discussed. A survey of attending GRAPPA members was held to collect data on the current and planned future use of MTX across the world ${ }^{15}$.

The International Dermatology Outcome Measures (IDEOM) psoriasis working group presented an overview of its work and discussed its efforts to agree on meaningful, valid, and feasible outcome measures in psoriasis. The PsA workgroup focused on the measurement of PsA symptoms in psoriasis clinical trials and the measurement of nonspecific musculoskeletal symptoms among patients with psoriasis in psoriasis longitudinal clinical trials and cohort studies ${ }^{16}$.
In a session that discussed the need to develop and update treatment recommendations for optimal treatment approaches for patients with PsA, the many recent, significant advances related to therapies and treatment approaches for PsA were discussed. Because of these advances, the process to update the recommendations has begun, and the basis for the approach that will be taken for the next version of the GRAPPA PsA treatment recommendations was reviewed.

The GRAPPA-Outcome Measures in Rheumatology (OMERACT) PsA working group reported at the 2019 GRAPPA annual meeting on its work to develop a core outcome set for PsA. The working group prioritized 4 domains, including musculoskeletal disease activity (enthesitis and dactylitis), fatigue, physical function, and structural damage ${ }^{17}$.

The GRAPPA ultrasound (US) working group presented its recent work and discussed its goal to create a sonographic enthesitis scoring system to optimize the evaluation of enthesitis in patients with PsA using US through the development of a diagnostic US enthesitis tool (DUET) ${ }^{18}$.

Members received updates on several ongoing educational and research efforts. Among them were updates on research and pilot research grants; GRAPPA's PRP; education, including the slide collection; and additional efforts related to advancing the understanding of disease aspects, including axial and US enthesitis projects, as well as the early psoriatic disease systematic literature review and magnetic resonance imaging ${ }^{19}$.

At the conclusion of the GRAPPA meeting, members discussed future action items in a business meeting. The next annual meeting will be held in Brooklyn, New York, USA, in July 2020.

\section{ACKNOWLEDGMENT}

Special thanks go to Sharon Andrews for her tireless organizational efforts, which kept the meeting running smoothly.

\section{REFERENCES}

1. Mease PJ, Gladman DD. Prologue: 2009 Group for Research and Assessment of Psoriasis and Psoriatic Arthritis (GRAPPA). J Rheumatol 2011;38:522-5.

2. Mease PJ, Gladman DD. Prologue: 2010 Group for Research and Assessment of Psoriasis and Psoriatic Arthritis (GRAPPA). J Rheumatol 2012;39:391-3

3. Mease PJ, Gladman DD. Prologue: 2011 Group for Research and Assessment of Psoriasis and Psoriatic Arthritis (GRAPPA). J Rheumatol 2012;39:2181-3.

4. Mease PJ, Boehncke WH, Gladman DD. Prologue: 2012 Annual Meeting of the Group for Research and Assessment of Psoriasis and Psoriatic Arthritis (GRAPPA). J Rheumatol 2013;40:1407-9.

5. Boehncke WH, Gladman DD. Prologue: 2013 Annual Meeting of the Group for Research and Assessment of Psoriasis and Psoriatic Arthritis (GRAPPA). J Rheumatol 2014;41:1194-6.

6. Boehncke WH, Gladman DD. Prologue: 2014 Annual Meeting of the Group for Research and Assessment of Psoriasis and Psoriatic Arthritis (GRAPPA). J Rheumatol 2015;42:2011-13. 
7. Boehncke WH, Gladman DD, Helliwell PS. Prologue: 2015 Annual Meeting of the Group for Research and Assessment of Psoriasis and Psoriatic Arthritis (GRAPPA). J Rheumatol 2016;43:949-51.

8. Helliwell PS, Gladman DD, Gottlieb AB. Prologue: 2016 Annual Meeting of the Group for Research and Assessment of Psoriasis and Psoriatic Arthritis (GRAPPA). J Rheumatol 2017;44:658-60.

9. Helliwell PS, Gladman DD, Gottlieb AB. Prologue: 2017 Annual Meeting of the Group for Research and Assessment of Psoriasis and Psoriatic Arthritis (GRAPPA). J Rheumatol Suppl 2018;94:1-3.

10. Callis Duffin K, Gladman DD, Gottlieb AB, Goel N. Prologue: 2018 Annual Meeting of the Group for Research and Assessment of Psoriasis and Psoriatic Arthritis (GRAPPA). J Rheumatol Suppl 2019;95:1-3.

11. Hughes CD, van Mens LJ, Boehncke WH, Ritchlin CT. GRAPPA Trainees Symposium 2019: a report from the GRAPPA 2019 Annual Meeting. J Rheumatol Suppl. 2020;96:4-10.

12. Tillett W, McHugh N, Orbai AM, Ogdie A, Leung YY, Coates LC, et al. Outcomes of the 2019 GRAPPA Workshop on continuous composite indices for the assessment of psoriatic arthritis and membership-recommended next steps. J Rheumatol Suppl. 2020;96:11-18.

13. Ritchlin CT, Pennington SR, Reynolds NJ, FitzGerald O. Moving toward precision medicine in psoriasis and psoriatic arthritis. J Rheumatol Suppl. 2020;96:19-24.
14. Waxman R, Stober C, Jadon DR, Orbai AM, Chandran V, Ogdie A, et al. Proceedings of the 2019 GRAPPA Collaborative Research Network meeting. J Rheumatol Suppl. 2020;96:25-30.

15. Coates LC, Merola JF, Grieb SM, Mease PJ, Callis Duffin K. Methotrexate in psoriasis and psoriatic arthritis. J Rheumatol Suppl. 2020;96:31-5.

16. Perez-Chada LM, Merola JF, Armstrong AW, Gottlieb AB. Report of the Skin Research Workgroups from the GRAPPA 2019 Annual Meeting. J Rheumatol Suppl. 2020;96:36-40.

17. Leung YY, Tillett W, Orbai AM, Ogdie A, Eder L, Coates LC, et al. The GRAPPA-OMERACT Working Group: 4 Prioritized Domains for Completing the Core Outcome Measurement Set for PsA 2019 Updates. J Rheumatol Suppl. 2020;96:45-7.

18. Eder L, Kaeley GS, Aydin SZ. Development and validation of a sonographic enthesitis instrument in psoriatic arthritis: the GRAPPA Diagnostic Ultrasound Enthesitis Tool (DUET) project. J Rheumatol Suppl. 2020;96:48-52.

19. Goel N, Coates LC, De Marco G, Eder L, FitzGerald O, Helliwell P, et al. GRAPPA 2019 Project Report. J Rheumatol Suppl. 2020;96:53-7. 